\title{
A Single-Dose, Single-Period Pharmacokinetic Assessment of an Extended-Release Orally Disintegrating Tablet of Methylphenidate in Children and Adolescents with Attention-Deficit/Hyperactivity Disorder
}

\author{
Ann Childress, MD, Jeffrey Newcorn, MD, Jeffrey G. Stark, PhD, Russ McMahen, BS, \\ Mark Tengler, $\mathrm{BS}^{4}$, and Carolyn Sikes, $\mathrm{PhD}^{4}$
}

\begin{abstract}
Objective: To determine the pharmacokinetic (PK) profile of a proprietary formulation of methylphenidate (MPH) in children and adolescents with attention-deficit/hyperactivity disorder (ADHD) in a phase 1 study. Methylphenidate extended-release orally disintegrating tablets (MPH XR-ODTs) combine two technologies in a single-tablet formulation—an extended-release profile that was designed for once-daily dosing in an ODT that does not require water or chewing for ingestion.

Methods: This was a single-dose, open-label, single-period, single-treatment study, in which 32 children with ADHD who were receiving MPH in doses of 40 or $60 \mathrm{mg}$ before beginning the study each received a $60-\mathrm{mg}$ dose $(2 \times 30 \mathrm{mg})$ of MPH XRODT. The following plasma PK parameters of MPH were determined for participants grouped by age $(6-7,8-9,10-12$, and 13-17 years old): maximum concentration $\left(\mathrm{C}_{\max }\right)$, time to maximum concentration $\left(\mathrm{T}_{\max }\right)$, elimination half-life $\left(\mathrm{T}_{1 / 2}\right)$, area under the curve from 0 hours to infinity $\left(\mathrm{AUC}_{\text {inf }}\right)$, oral clearance $(\mathrm{CL} / \mathrm{F})$, and volume of distribution in the terminal phase $(\mathrm{Vz} /$ F). Safety and tolerability were also assessed.

Results: A total of 32 participants received the study drug. For all participants, plasma concentration-time profiles of MPH exhibited a broad peak after administration of MPH XR-ODT through $\sim 8$ hours, indicating extended release from the formulation, followed by an apparent first-order elimination phase. As age increased, MPH exposure decreased and mean estimates of CL/F increased; however, weight-normalized CL/F values were comparable across age groups. Similarly, mean estimates of $\mathrm{Vz} / \mathrm{F}$ increased with age, but weight-normalization decreased differences across age groups, with the exception of the youngest age group, which had higher values. All adverse events (AEs) were mild.

Conclusion: This XR-ODT formulation of MPH demonstrated weight-normalized clearance rates that were consistent across all age groups, a PK profile consistent with once-daily dosing, and an AE profile consistent with this class of medication in children and adolescents with ADHD.
\end{abstract}

\section{Introduction}

A TTENTION-DEFICIT/HYPERACTIVITY DISORDER (ADHD) is a chronic neurobehavioral disorder affecting an estimated $7 \%$ of the population aged 18 years and under worldwide, and approximately half of the youth diagnosed with ADHD continue to have symptoms in adulthood (Kolar et al. 2008; Thomas et al. 2015). Psychostimulant medications, such as methylphenidate (MPH) and amphetamines, are widely regarded as offering the most effective control of core ADHD symptomatology and are generally well tolerated (Marcus et al. 2005; Antshel et al. 2011; Coghill et al. 2013; Felt et al. 2014).

There are many available formulations of both stimulant classes, including immediate-release, short-duration, and extended-release medications (Chavez et al. 2009). For MPH formulations, the efficacy of any particular formulation is related to its pharmacokinetic (PK) profile, as a formulation's PK profile over the day

\footnotetext{
${ }^{1}$ Center for Psychiatry and Behavioral Medicine, Inc., Las Vegas, Nevada.

${ }^{2}$ Department of Psychiatry, Icahn School of Medicine at Mount Sinai, New York City, New York.

${ }^{3}$ Worldwide Clinical Trials, Austin, Texas.

${ }^{4}$ Neos Therapeutics, Inc., Grand Prairie, Texas.
}

(c) Ann Childress et al. 2016; Published by Mary Ann Liebert, Inc. This Open Access article is distributed under the terms of the Creative Commons Attribution Noncommercial License (http://creativecommons.org/licenses/by-nc/4.0/) which permits any noncommercial use, distribution, and reproduction in any medium, provided the original author(s) and the source are credited. 
predicts its duration of efficacy (Coghill et al. 2013). While some children with ADHD continue to use immediate-release stimulant formulations as their primary medication or to augment other ADHD medications, long-acting formulations are currently preferred and more commonly prescribed (McCracken et al. 2003; Swanson and Hechtman 2005). Immediate-release stimulant formulations offer a 3- to 6-hour duration of action compared with longer-acting stimulant formulations, which offer an 8- to 12-hour duration of action (Chavez et al. 2009). Long-acting extendedrelease formulations allow for once-daily dosing and obviate the need for interruptions during the day, thus reducing the stigma associated with redosing during school hours (Feldman and Belanger 2009).

Long-acting MPH formulations deliver active drug through different methods. Many extended-release formulations produce an initial bolus delivery of immediate-release MPH that produces peak plasma concentrations 1-4 hours postdose followed by a long, controlled delivery of MPH that maintains plasma concentrations in the afternoon, effectively controlling symptoms for 8-12 hours after the initial dose (Swanson et al. 2004; Wolraich and Doffing 2004). Available extended-release formulations for ADHD include tablets, capsules, oral liquid suspensions, and a transdermal patch that can be worn up to 9 hours per day (Chavez et al. 2009). Additional stimulant formulations are currently in the pipeline (Childress and Tran 2016). Some of the long-acting stimulant capsules can be opened and sprinkled on certain foods (e.g., applesauce): however, not all long-acting medications can be sprinkled on foods or dissolved, and chewing or crushing is never permitted for any solid extended-release formulation (Wigal et al. 2013; Adderall $\mathrm{XR}^{\circledR}$ Shire US Inc., Wayne, PA; Ritalin LA ${ }^{\circledR}$ Novartis Pharmaceuticals Co., East Hanover, NJ; Focalin $\mathrm{XR}^{\circledR}$ Novartis Pharmaceuticals Co., East Hanover, NJ; Metadate CD ${ }^{\circledR}$ UCB Inc., Smyrna, GA; Vyvanse ${ }^{\circledR}$ Shire US, Inc., Wayne, PA). Importantly, if the formulation is altered, the full dose of the extended-release stimulant may not be reliably administered and bioavailability of the medication may change.

When patients find it difficult to swallow medications, the results of treatment are often compromised. One study conducted in adults ( $>18$ years of age) who had a variety of medical disorders and who were taking multiple medications each day found that patients frequently avoided taking their medications or altered their oraldose formulation to help with pill-swallowing difficulties by crushing or opening (Marquis et al. 2013). This practice can result in dose dumping of extended-release formulations (i.e., early release of a large amount or even most of the medication). Tablets and capsules should not be crushed or chewed, as these alterations to the route of administration can lead to adverse events (AEs) (Pleak 1995; Paparella 2010). Chewing MPH formulations with modifiedrelease profiles has been reported to increase side effects such as nausea, abdominal pain, and disrupted eating while decreasing efficacy, likely due to the high peak plasma concentrations of active drug achieved in a short duration of time (Pleak 1995).

Difficulty in swallowing, or not wanting to swallow, solid oral dosage forms can also result in compromised adherence, leading to missed doses or discontinuation of drug therapy (Wigal et al. 2013). One study evaluating medication acceptance in children found that $\sim 70 \%$ of children $5-9$ years old and $30 \%$ of children $10-14$ years old could not easily swallow tablets and capsules similar in size to many of the available stimulant medications (Polaha et al. 2008). In some children, behavioral therapy was successful in addressing pill-swallowing aversions (Beck et al. 2005). The extent of pill aversion among patients with ADHD has not yet been systemati- cally studied, and the potential impact of formulation on adherence in treating youth with ADHD is not yet known. However, delivering medication through formulations that are acceptable to children and that suit their size, age, physiologic condition, and treatment requirements is a recommended strategy in pediatrics to improve therapeutic outcomes (Ivanovska et al. 2014).

The availability of pediatric formulations has increased over recent years, but the market is largely limited to a few therapeutic areas, including respiratory and central nervous system (CNS) medications, hormones, and anti-infectives, emphasizing the unmet need for alternative formulations suitable for children in other disease areas (Balakrishnan et al. 2006; Ivanovska et al. 2014).

A new orally disintegrating tablet (ODT) formulation of MPH, which provides a PK profile consistent with once-daily dosing, has been developed by Neos Therapeutics, Inc. (NT0102 [MPH XRODT]; Childress et al. 2016). Orally disintegrating tablets that dissolve or disintegrate in the mouth without water traditionally have had immediate-release PK profiles (Saharan and Singh 2015); however, this formulation is the first extended-release MPH ODT. The XR-ODT formulation is made possible through ionexchange resin technology. When the MPH salt is dissolved in the presence of the exchange resin, the positively charged mobile ion of the exchange resin $\left(\mathrm{Na}^{+}\right)$is replaced by the positively charged MPH molecule, resulting in stable MPH microparticles. MPH microparticles are either coated (extended-release) or uncoated (immediaterelease) and compressed into ODTs. The coating controls the timing of drug release, enabling a modified release profile as the ODT formulation contains $\sim 30 \%$ immediate-release $\mathrm{MPH}$ and $\sim 70 \%$ extended-release MPH. The ODT disintegrates in the mouth without water and the disintegrated portions of the ODT are swallowed together with saliva.

The primary objective of this phase 1 study was to determine the PK profile of MPH XR-ODT in children and adolescents (6-17 years old) with ADHD.

\section{Methods}

This single-dose, open-label, single-period, single-treatment PK study was conducted at the Atlanta Center for Medical Research in accordance with the clinical research guidelines established by the basic principles defined in the United States Investigational New Drug regulations (21 Code of Federal Regulations Parts 50, 56, and 312 ), the principles enunciated in the International Conference on Harmonisation Guidelines for Good Clinical Practice, and the most recent guidelines of the Declaration of Helsinki (ICH 1996; World Medical Association 2013); it was approved by the IntegReview Ethical Review Board. Each participant and parent/legal guardian was provided with oral and written information describing the nature and duration of the study, in English. The participant must have had a parent or legal guardian who gave written informed consent for the child to participate in the study. The parent or guardian must have been able to read, speak, and understand English and be mentally and physically competent to provide written informed consent for their child. Signed assent was obtained from all children aged 6 years or older, or as per local or site requirements. Written informed consent/assent from both the parent/ caregiver and children $\geq 6$ years of age was obtained before performing any screening visit study-specific evaluations.

\section{Participant demographics}

Participants in this study were male and female, aged 6-17 years, and were stratified into four age groups: $6-7,8-9,10-12$, and 
13-17 years. Before study initiation, all participants were screened within 3 weeks before administration of study drug. All participants were required to have a primary diagnosis of ADHD (any subtype) based on Diagnostic and Statistical Manual of Mental Disorders, 4th Ed., Text Revision (DSM-IV-TR) criteria, as established by the Kiddie Schedule for Affective Disorders and Schizophrenia for School-Age Children-Present and Lifetime version (K-SADSPL) (Kaufman et al. 1997; American Psychiatric Association 2000). Investigators also screened for comorbid psychiatric disorders; the Pediatric Baseline Version of the Columbia Suicide Severity Rating Scale (C-SSRS) was used to screen for suicidal ideation and behavior (Posner et al. 2010).

\section{Inclusion/exclusion criteria}

Study participants were required to have had a favorable response to treatment with a stable dose of 40-60 mg of MPH hydrochloride (Metadate $\mathrm{CD}^{\circledR}$ ) or a comparable dose(s) of an extendedrelease or immediate-release formulation of MPH hydrochloride (based on investigator determination) for at least 1 month and to have been under treatment for ADHD with an MPH-containing medication for a minimum of 3 consecutive months before study screening; this ensured that participants would be reasonably able to tolerate the medication dose used in this study. To confirm prior MPH use, a separate urine drug test obtained at screening tested for MPH and was expected to be positive. Pregnant females were excluded from the study and reliable contraception and urine pregnancy tests were required as appropriate. Exclusion criteria included a diagnosis or history of a tic disorder or Tourette's syndrome, as well as any family history of Tourette's syndrome; long QT syndrome or any clinically significant electrocardiogram (ECG) abnormality; history of suicidal ideation or behavior; other clinically significant psychiatric illnesses or substance abuse disorders; and clinically significant medical conditions, particularly cardiovascular disorders or any disorder or concomitant medications that could potentially alter the absorption, distribution, metabolism, or excretion of the study drug.

\section{Medication}

The study drug was an extended-release ODT formulation of $\mathrm{MPH}$, provided as 30-mg tablets, for a total single-study dose of $60 \mathrm{mg}(2 \times 30 \mathrm{mg}$ ODT) comprising both $d$-MPH and $l$-MPH enantiomers in a racemic mixture. A 60-mg dose was selected for this study because $60 \mathrm{mg}$ is the maximum labeled dose for the reference formulation. Participants discontinued their current ADHD treatment regimen at least 4 days before dosing with MPH XR-ODT. Urine screening was performed to confirm that participants had been washed out from their usual MPH medication and were not using other ADHD medications or drugs of abuse. Gas chromatography/mass spectrometry was used to confirm the presence of the suspect analyte.

\section{Procedures}

Participants were admitted to the research facility the evening before dosing, fasted for at least 10 hours overnight, and then received a single dose of the study medication. MPH XR-ODTs were administered without water (other than a small mouth rinse to wet the mouth, which the participants spat out before study drug administration) and allowed to disintegrate in the mouth. The participants were permitted to move the study drug around in their mouth as needed while it disintegrated but were instructed not to chew or swallow the ODT intact. A mouth check was performed immediately after the dose was administered, to ensure that the disintegrated portion of the ODT had been swallowed. No food was permitted until 4 hours after dosing.

Eight blood samples for PK analysis were drawn during the treatment period; $3 \mathrm{~mL}$ blood samples were obtained before dosing and at selected times through 24 hours postdose: time 0 (predose) and at $0.75,2,3.5,5.5,8,12$, and 24 hours postdose. All PK samples, except the 24-hour blood draw, were collected while participants were inpatients. Plasma samples were analyzed for $d$-MPH and $l$-MPH using a validated liquid chromatography-mass spectrometry-mass spectrometry assay; concentration-time data for total MPH ( $d$ - $+l$-isomers summed) were used in the PK analysis. PK parameters for MPH were calculated for $d$-methylphenidate and $l$-methylphenidate separately as exploratory analyses.

Plasma samples were analyzed for $d$-MPH and $l-\mathrm{MPH}$ by Worldwide Clinical Trials; concentrations were reported in $\mathrm{ng} / \mathrm{mL}$ to three significant figures and concentrations below limit of quantification (BLQ) were set to zero $(0.00 \mathrm{ng} / \mathrm{mL})$ in the data summarization. The analytical method was validated for a range of $0.250-50.0 \mathrm{ng} / \mathrm{mL}$ for $d-\mathrm{MPH}$ and $0.0100-2.00 \mathrm{ng} / \mathrm{mL}$ for $l-\mathrm{MPH}$, based on $0.100 \mathrm{~mL}$ of K2-EDTA plasma. Quality control (QC) samples for $d$-MPH ranged from 0.750 to $40.0 \mathrm{ng} / \mathrm{mL}$; the precision and accuracy for $d$-MPH analysis were $7.0 \%$ coefficient of variation $(\mathrm{CV})$ and $+6.5 \%$, respectively. QC samples for $l$-MPH ranged from 0.0300 to $10.0 \mathrm{ng} / \mathrm{mL}$; the precision and accuracy for $l$-MPH analysis were $8.2 \% \mathrm{CV}$ and $+7.7 \%$, respectively. Study data were collected using Analyst ${ }^{\circledR}$ (Version 1.4.2 or 1.6.1; Applied Biosystems/MDS Sciex) and Watson Laboratory Information Management System $^{\text {TM }}$ (LIMS, Version 7.2.0.03; Thermo Fisher Scientific) software. The concentration-time data were transferred from Watson LIMS directly to Phoenix WinNonlin (Version 6.3; Pharsight Corporation) using the Custom Query Builder option for analysis. PK calculations were performed by noncompartmental methods in WinNonlin.

In the PK analysis, BLQ concentrations were treated as zero from time-zero up to the time at which the first quantifiable concentration was observed; embedded and/or terminal concentrations BLQ were treated as "missing." Full precision concentration data (not rounded to three significant figures) and actual sample times were used for all PK and statistical analyses. The data from this study demonstrated that the $l$-isomer represents a negligible fraction of the plasma concentration in contrast to the more pharmacologically active $d$-isomer, which is consistent with the results from previous studies of oral MPH (Healand and Pierce 2006). The following plasma PK parameters were determined: maximum concentration $\left(\mathrm{C}_{\max }\right)$, time to maximum concentration $\left(\mathrm{T}_{\max }\right)$, elimination half-life $\left(\mathrm{T}_{1 / 2}\right)$, area under the curve from time 0 hours to infinity $\left(\mathrm{AUC}_{\mathrm{inf}}\right)$, oral clearance $(\mathrm{CL} / \mathrm{F})$, and volume of distribution in the terminal phase $(\mathrm{Vz} / \mathrm{F})$; weight-normalized values of $\mathrm{CL} / \mathrm{F}$ and $\mathrm{Vz} / \mathrm{F}$ were also reported, as $\mathrm{CL} / \mathrm{F} / \mathrm{kg}$ and $\mathrm{Vz} / \mathrm{F} / \mathrm{kg}$, respectively. $\mathrm{PK}$ parameters were summarized using descriptive statistics, and the geometric means and $95 \%$ confidence intervals (CIs) were calculated for weight-normalized CL/F and $\mathrm{Vz} / \mathrm{F}$ in each age group to determine if the $95 \%$ CIs were within the target range of $60 \%-140 \%$.

Safety data, including AEs (reported or observed), physical examinations, 12-lead ECGs, body weight, vital signs, clinical laboratory tests, and urine pregnancy tests, were collected. Urine was tested for the presence of alcohol, amphetamines, barbiturates, benzodiazepines, cocaine, methadone, opiates, phencyclidine, propoxyphene, and tetrahydrocannabinol/marijuana at visit 1 (screening) and visit 2 (check-in for the study period). If urine drug screen results were positive, the corresponding gas chromatography/mass 
Table 1. Participant Demographics AND BaSEline ChaRACTERISTICS

\begin{tabular}{lc}
\hline Parameter & Study population \\
\hline Sex, $n(\%)$ & \\
$\quad$ Total, male/female $(N=32)$ & $24(75.0) / 8(25.0)$ \\
Age group 6-7 years, & $5(62.5) / 3(37.5)$ \\
$\quad$ male/female $(n=8)$ & $6(75.0) / 2(25.0)$ \\
Age group 8-9 years, & \\
$\quad$ male/female $(n=8)$ & $6(75.0) / 2(25.0)$ \\
Age group 10-12 years, & \\
$\quad$ male/female $(n=8)$ & $7(87.5) / 1(12.5)$ \\
Age group 13-17 years, & \\
$\quad$ male/female $(n=8)$ & $11(34.4)$ \\
Race, $n(\%),(N=32)$ & $10(62.5)$ \\
$\quad$ White & \\
Black or African American & $10.4 \pm 3.7$ \\
$\quad$ White and Black or African American & $6.0-17.0$ \\
Age, years, $(N=32)$ & \\
Mean \pm SD & $18.0 \pm 2.8$ \\
Range & \\
BMI, kg/m ${ }^{2},(N=32)$ & $25.9 \pm 4.7$ \\
$\quad$ Mean \pm SD & $31.5 \pm 5.6$ \\
Weight, kg, mean \pm SD & $38.1 \pm 6.6$ \\
Age group 6-7 years, $(n=8)$ & $63.0 \pm 9.2$ \\
$\quad$ Age group 8-9 years, $(n=8)$ & \\
Age group 10-12 years, $(n=8)$ & \\
Age group 13-17 years, $(n=8)$ & \\
\hline
\end{tabular}

BMI, body mass index; $n$, number of participants; $N$, all participants $\mathrm{SD}$, standard deviation.

spectrometry confirmatory test was performed to confirm the suspect analyte. A separate urine drug screen was performed to assess for the presence of MPH at screening.

\section{Results}

\section{Participants}

A total of 33 participants enrolled in the study, with 1 participant discontinuing before receiving any study drug. Participants ranged in age from 6 to 17 years, with a greater percentage being male
(75\%) and black or African American (62.5\%). Detailed demographic information and baseline characteristics of study participants are shown in Table 1.

\section{PK assessments}

The primary prespecified analysis of this study was to present the mean ( \pm standard deviation [SD]) plasma $d+l \mathrm{MPH}$ concentrationtime data by age group as shown in Figure 1. Additionally, the mean $( \pm \mathrm{SD}) \mathrm{MPH}$ concentration-time data are presented for all participants in Figure 2. For all 32 participants, quantifiable plasma concentrations of MPH were observed at the first postdose PK time point ( 0.75 hours) and throughout the 24 -hour sampling interval. As shown in Figures 1 and 2, plasma concentration-time profiles of MPH exhibited a broad peak after administration of MPH XR-ODT through $\sim 8$ hours, indicating extended release from the formulation, followed by an apparent first-order elimination phase.

The PK parameters for MPH are presented both by age group and for all participants in Table 2. MPH XR-ODT $60 \mathrm{mg}$ displayed a PK profile similar to that of other long-acting MPH formulations, which achieve peak plasma concentration within several hours of dosing, followed by a slow descending MPH plasma concentration (Swanson et al. 2004). After a fixed 60-mg dose of MPH XR-ODT, the mean (SD) $\mathrm{C}_{\max }$ was 30.1 (10.6) $\mathrm{ng} / \mathrm{mL}$ for all participants $(n=32)$, occurring at mean (SD) $\mathrm{T}_{\max }$ of 4.81 (1.48) hours. Mean (SD) overall systemic exposure to $\mathrm{MPH}$, as measured by $\mathrm{AUC}_{\mathrm{inf}}$, was $299(104) \mathrm{ng} \cdot$ hour/mL $(n=30)$. Notable differences were observed in PK parameters across age groups with the 6- to 7-year age group exhibiting higher maximum plasma concentrations compared with the older age groups. The mean (SD) $\mathrm{C}_{\max }$ ranged from $20.6(5.97) \mathrm{ng} / \mathrm{mL}$ for the 13- to 17-year age group to 38.1 (7.88) $\mathrm{ng} / \mathrm{mL}$ for the 6- to 7 -year age group, occurring at median $\mathrm{T}_{\max }$ between 3.5 and 5.5 hours. Likewise, overall systemic exposure to $\mathrm{MPH}$, as measured by $\mathrm{AUC}_{\mathrm{inf}}$, decreased with age; mean (SD) $\mathrm{AUC}_{\text {inf }}$ ranged from 190 (63) $\mathrm{ng} \cdot \mathrm{hour} / \mathrm{mL}$ for the 13- to 17-year age group to $378(104) \mathrm{ng} \cdot$ hour/mL for the 6- to 7-year age group. This decrease in MPH exposure with age reflects the established increase in MPH clearance with age seen in another MPH formulation (Concerta ${ }^{\circledR}$ Janssen Pharmaceuticals, Inc., Titusville, $\mathrm{NJ}$ ); mean (SD) CL/F ranged from 169 (45) L/hour for the

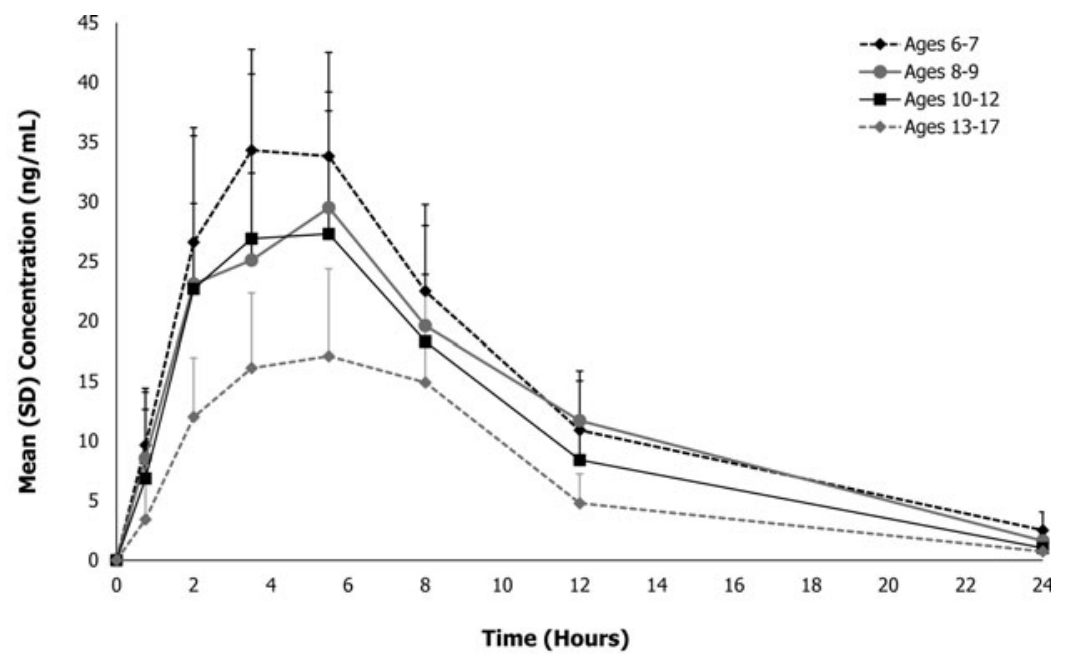

FIG. 1. Mean total methylphenidate plasma concentration-time profiles for MPH XR-ODT under fasted conditions in children and adolescents by age. MPH XR-ODT, methylphenidate extended-release orally disintegrating tablets. 


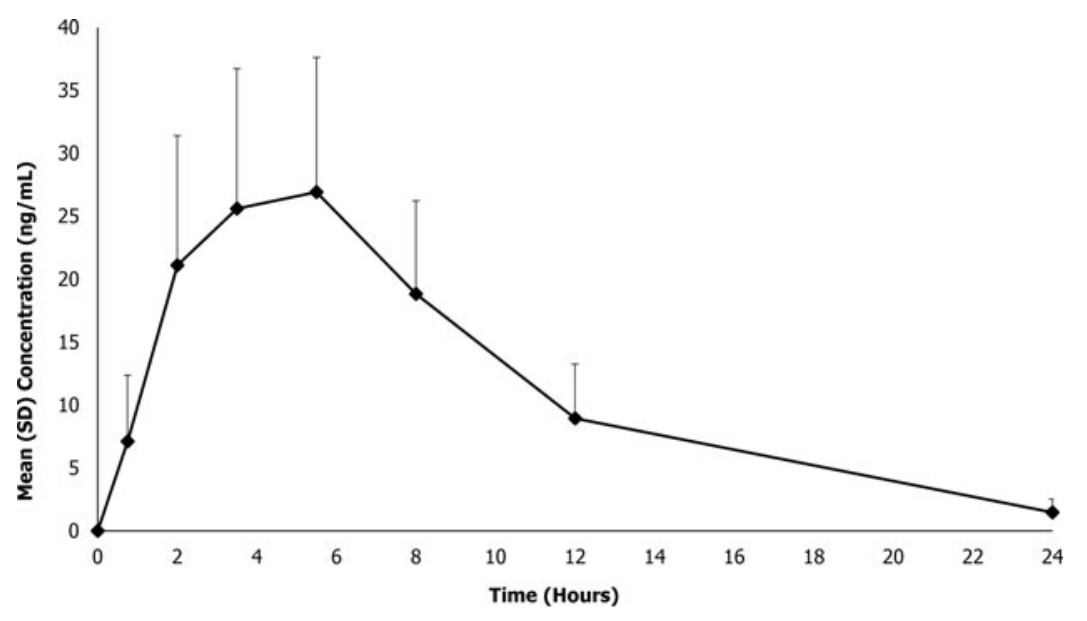

FIG. 2. Mean total methylphenidate plasma concentration-time profiles for MPH XR-ODT under fasted conditions in children and adolescents. MPH XR-ODT, methylphenidate extended-release orally disintegrating tablets.

6- to 7-year age group to 343 (99) L/hour for the 13- to 17-year age group. However, appreciable differences in CL/F were not observed after these values were adjusted for the patients' weight; the geometric mean $\mathrm{CL} / \mathrm{F} / \mathrm{kg}$ ranged from 5.35 to $6.44 \mathrm{~L} /$ (hour $\cdot \mathrm{kg}$ ). As shown in Table 3, the 95\% CIs for the geometric mean $\mathrm{CL} / \mathrm{F} / \mathrm{kg}$ and $\mathrm{Vz} / \mathrm{F} / \mathrm{kg}$ fell within the target range of $60 \%-$ $140 \%$ for each age group.

\section{Reported adverse events}

Of the 33 participants enrolled in this study, 32 received the study medication. Consent was withdrawn by one participant who was discontinued early from the study before taking any study drug. There were a total of 34 AEs, with 22 participants (68.8\%) experiencing an AE: 7 in age group 1 (6-7 years old), 7 in age group 2 (8-9 years old), 6 in age group 3 (10-12 years old), and 2 in age group 4 (13-17 years old). All 34 AEs were judged by the investigators to be mild and 33 were assessed as being related to the study drug. The most common AEs, occurring in $>5 \%$ of participants, are listed in Table 4 and included increased heart rate, decreased appetite, nausea, and vomiting. The nature of the treatment-emergent AEs reported was consistent with the mechanism of action for the study medication. Clinical laboratory, ECG, and physical examination evaluations were completed with no clinically significant findings. There were no deaths, nonfatal serious AEs, or discontinuations due to AEs.

\section{Discussion}

The availability of alternative MPH dosage forms, including this novel XR-ODT formulation of MPH, may allow for increased flexibility for healthcare providers when choosing a formulation to align with individual patient needs (Coghill et al. 2013). The average $\mathrm{T}_{\max }$ (4.25-5.31 hours) for total MPH was similar (although not identical) for all age groups and was consistent with previous reports of other long-acting MPH formulations (Ritalin LA ${ }^{\circledR}$ Novartis Pharmaceuticals Co., East Hanover, NJ; Metadate $\mathrm{CD}^{\circledR} \mathrm{UCB}$ Inc., Smyrna, GA). Apparent differences in $\mathrm{T}_{\max }$ across age groups reflect small differences in the plasma concentrations of MPH stemming from the extended-release characteristics of the formulation, as seen in Figures 1 and 2. Quantifiable MPH concentrations were observed at the first PK time point ( 0.75 hours), and measurable concentrations of total MPH were observed throughout the 24-hour sampling interval for all participants, consistent with available once-daily MPH formulations (Wigal et al. 2007). The observed differences in exposure parameters were largely due to age-related weight disparities between the groups, except for the youngest age group (6-7 years), in which exposure was higher than in the other age groups, a previously observed phenomenon (Wigal

Table 2. Total Methylphenidate Pharmacokinetic Parameters of MPH XR-ODT

\begin{tabular}{lccccc}
\hline Parameter & $\begin{array}{c}6-7 \text { years } \\
\text { old }(\mathrm{n}=8)\end{array}$ & $\begin{array}{c}8-9 \text { years } \\
\text { old }(\mathrm{n}=8)\end{array}$ & $\begin{array}{c}\text { 10-12 years } \\
\text { old }(\mathrm{n}=8)\end{array}$ & $\begin{array}{c}\text { 13-17 years } \\
\text { old }(\mathrm{n}=8)\end{array}$ & $\begin{array}{c}\text { Total } \\
(\mathrm{N}=32)\end{array}$ \\
\hline $\mathrm{T}_{\max }$ (hours), median (range) & $3.5(3.5-5.5)$ & $5.5(3.5-8.0)$ & $4.5(2.0-8.0)$ & $5.5(3.5-8.0)$ & $5.5(2.0-8.0)$ \\
Mean $\pm \mathrm{SD}$ & $4.25 \pm 1.04$ & $5.06 \pm 1.55$ & $4.62 \pm 1.87$ & $5.31 \pm 1.41$ & $4.81 \pm 1.48$ \\
$\mathrm{C}_{\max }(\mathrm{ng} / \mathrm{mL})$, mean $\pm \mathrm{SD}$ & $38.1 \pm 7.88$ & $30.7 \pm 7.49$ & $30.7 \pm 12.9$ & $20.6 \pm 5.97$ & $30.1 \pm 10.6$ \\
$\mathrm{AUC}$ & $378 \pm 104$ & $336 \pm 37^{\mathrm{a}}$ & $285 \pm 95$ & $190 \pm 63^{\mathrm{a}}$ & $299 \pm 104^{\mathrm{b}}$ \\
$\mathrm{T}_{1 / 2}$ (hours), mean $\pm \mathrm{SD}$ & $5.03 \pm 1.24$ & $4.34 \pm 0.89^{\mathrm{a}}$ & $3.87 \pm 0.36$ & $3.92 \pm 0.33^{\mathrm{a}}$ & $4.30 \pm 0.91^{\mathrm{b}}$ \\
$\mathrm{Vz} / \mathrm{F}(\mathrm{L})$, mean $\pm \mathrm{SD}$ & $1191 \pm 269$ & $1140 \pm 322^{\mathrm{a}}$ & $1295 \pm 439$ & $1901 \pm 412^{\mathrm{a}}$ & $1372 \pm 460^{\mathrm{b}}$ \\
$\mathrm{CL} / \mathrm{F}(\mathrm{L} / \mathrm{hour})$, mean $\pm \mathrm{SD}$ & $169 \pm 45$ & $180 \pm 20^{\mathrm{a}}$ & $230 \pm 69$ & $343 \pm 99^{\mathrm{a}}$ & $229 \pm 92^{\mathrm{b}}$ \\
\hline
\end{tabular}

${ }_{n=7}^{\mathrm{a}}{ }_{n=\mathrm{AUC}} \mathrm{inf}_{1 / 21 / 2}, \mathrm{Vz} / \mathrm{F}$, and $\mathrm{CL} / \mathrm{F}$ could not be estimated for one patient in this age group.

${ }^{\mathrm{b}} N=30$.

$\mathrm{AUC}_{\mathrm{inf}}$, area under the curve from time 0 hours to infinity; CL/F, oral clearance; $\mathrm{C}_{\max }$, maximum plasma concentration; MPH XR-ODT, methylphenidate extended-release orally disintegrating tablets; $n$, number of participants; $N$, all participants; SD, standard deviation; $\mathrm{T}_{1 / 2}$, elimination halflife; $\mathrm{T}_{\max }$, time to maximum plasma concentration; $\mathrm{Vz} / \mathrm{F}$, volume of distribution in the terminal phase. 
Table 3. Statistical Analyses of Weight-Normalized Clearance and Volume of Distribution in the Terminal Phase of Total Methylphenidate by Age Group

\begin{tabular}{lccc}
\hline Parameter & $\mathrm{n}$ & Geometric mean $(95 \%$ CI) & Target CI interval range $(60 \%-140 \%)$ \\
\hline Age group 1 (6-7 years) & & & $27.4-64.0$ \\
Vz/F (L/kg) & 8 & $45.7(36.2-57.7)$ & $3.86-9.02$ \\
CL/F (L/[h/kg]) & 8 & $6.44(5.14-8.06)$ & $20.7-48.3$ \\
Age group 2 (8-9 years) & 7 & $34.5(29.5-40.3)$ & $3.35-7.83$ \\
Vz/F (L/kg) & 7 & $5.59(4.98-6.28)$ & $19.5-45.6$ \\
CL/F (L/[h/kg]) & & $32.6(25.0-42.5)$ & $3.52-8.22$ \\
Age group 3 (10-12 years) & 8 & $5.87(4.60-7.47)$ & $18.1-42.2$ \\
Vz/F (L/kg) & 8 & $30.1(25.2-36.0)$ & $3.21-7.49$ \\
CL/F (L/[h/kg]) & 7 & $5.35(4.24-6.73)$ & \\
Age group 4 (13-17 years) & 7 & & \\
Vz/F (L/kg) & & & \\
CL/F (L/[h/kg]) & &
\end{tabular}

$\mathrm{CI}$, confidence interval; CL/F/kg, weight-normalized oral clearance in the terminal phase; Vz/F/kg, weight-normalized volume of distribution in the terminal phase.

et al. 2007). According to previously reported PK/pharmacodynamic (PD) modeling data comparing two different formulations of extended-release MPH, superior efficacy at any point in time was achieved for the MPH formulation with the highest plasma concentration (Swanson et al. 2004); therefore, due to the notable differences observed in $\mathrm{C}_{\max }$ between age groups after a $60-\mathrm{mg}$ dose of MPH XR-ODT, future efforts toward determining a weightbased PK/PD efficacy model are warranted.

Consistent with previously published studies of MPH PK, estimates of $\mathrm{CL} / \mathrm{F}$ following oral MPH administration increased with age due to intrinsic body weight differences between younger children and adolescents (Wigal et al. 2007). However, when normalized by weight, CL/F values were comparable across age groups. Similarly, mean estimates of Vz/F of MPH increased with age, but the differences across the four age groups were less variable after weight normalization, with the exception of the youngest participants in the study (6-7 years old). The geometric means for $\mathrm{CL} / \mathrm{F} / \mathrm{kg}$ and $\mathrm{Vz} / \mathrm{F} / \mathrm{kg}$ of MPH and the respective $95 \%$ CIs were within the target range $(60 \%-140 \%)$ for each of the four age groups.

One limitation of this study is that the sample of females is not large enough to enable comparison of PK characteristics of males versus females. Evidence suggests that female adults have lower plasma concentrations as compared with their male counterparts after receiving the same dosage of MPH (Markowitz et al. 2003). The extent to which the gender composition of the different age groups influenced the PK results in this study is not known. An additional limitation is that this was a single-dose study. A previous study of children and adolescents demonstrated that MPH accumulation did occur when participants were monitored for 7 days while taking fixed daily doses of long-acting MPH (osmotic-release

Table 4. Summary of Adverse Events ( $>5 \%)$

\begin{tabular}{lc}
\hline Adverse event & Participants $(\mathrm{N}=32), \mathrm{n}(\%)$ \\
\hline Any adverse event (all mild) & $22(68.8)$ \\
Increased heart rate & $12(37.5)$ \\
Decreased appetite & $11(34.4)$ \\
Nausea & $2(6.3)$ \\
Vomiting & $2(6.3)$ \\
\hline
\end{tabular}

$n$, number of participants; $N$, all participants. oral system MPH) (Pierce et al. 2010). Yet the available evidence indicates that conventional extended-release tablet and capsule formulations of MPH do not accumulate (Ritalin LA $^{\circledR}$ Novartis Pharmaceuticals Co., East Hanover, NJ; Concerta ${ }^{\circledR}$ Janssen Pharmaceuticals, Inc., Titusville, NJ); therefore, we do not expect that the PK profile of MPH XR-ODT would be altered over time.

\section{Conclusions}

The PK profile of MPH XR-ODT formulation is consistent with once-daily dosing similar to currently available oral formulations. This formulation demonstrated a similar safety and efficacy profile to that of the available extended-release MPH tablets and capsules in a phase 3 clinical efficacy and safety trial in children with ADHD (NCT01835548). This study demonstrated efficacy of MPH XRODT in a laboratory classroom setting from 1 hour through 12 hours postdose (Childress et al. 2016).

The other noteworthy finding of this study is the correlation of plasma concentration with age and weight. The latter finding suggests that more attention should be paid to the effects of weight on MPH dosing in subsequent clinical trials. If the clinical utility of weight-based dosing is confirmed, this would represent an important recommendation for clinical practice.

\section{Clinical Significance}

This PK study of a novel MPH formulation, MPH XR-ODT, demonstrates a PK profile that is consistent with once-daily dosing, similar to available long-acting oral formulations of MPH. The new formulation disintegrates in the mouth without water and does not require chewing or swallowing an intact tablet. Orally disintegrating tablets have been suggested as effective alternatives to conventional tablet formulations for the treatment of another CNS disorder in adults (Dowson et al. 2002; Dowson and Charlesworth 2003). Orally disintegrating tablets also have been used successfully in children for treating various conditions, including asthma and nausea (Orapred ODT ${ }^{\circledR}$ Shionogi Inc., Atlanta, GA; Zofran ODT ${ }^{\circledR}$ GlaxoSmithKline., Research Triangle Park, NC). The extent to which different oral formulations affect treatment outcomes in ADHD remains unknown; however, MPH XR-ODTs may be an alternative to traditional extended-release stimulant formulations, as no measuring or opening capsules to sprinkle into food or liquid is required for ingestion. 


\section{Acknowledgments}

Editorial assistance was provided by Jennifer Tyson, $\mathrm{PhD}$, of AlphaBioCom, King of Prussia, PA, and supported by Neos Therapeutics, Inc., Grand Prairie, TX.

\section{Disclosures}

A.C. has received research support from, consulted with, acted as invited speaker for, and/or served on advisory boards for Alcobra Pharma, Arbor Pharmaceuticals, Forest Research Institute, Ironshore Pharmaceuticals, Lilly USA, Lundbeck, Neos Therapeutics, Inc., Neurovance, NextWave Pharmaceuticals, Noven Pharmaceuticals, Otsuka Pharmaceutical, Pfizer, Purdue Pharma, Rhodes Pharmaceuticals, Shire Pharmaceuticals, Sunovion Pharmaceuticals, Theravance Biopharma, and Tris Pharma.

J.N. is an advisor/consultant for Alcobra, BioBehavioral Diagnostics, Ironshore, Neos Therapeutics, Inc., NFL, Rhodes, Shire, and Sunovion (data and safety monitoring board) and has received research support from Enzymotec and Shire.

R.M. is an employee of Neos Therapeutics, Inc., with stock options. M.T. is an employee of Neos Therapeutics, Inc., with stock options. J.G.S. is an employee of Worldwide Clinical Trials.

C.S. is an employee of Neos Therapeutics, Inc., with stock options in Neos Therapeutics, Inc., and stock in Pfizer.

\section{References}

Adderall XR 2015 (Full Prescribing Information). Wayne (Pennysylvania), Shire US, Inc., 2015.

American Psychiatric Association: Diagnostic and Statistical Manual of Mental Disorders, 4th ed. Text Revision. Washington, DC: American Psychiatric Association, 2000.

Antshel KM, Hargrave TM, Simonescu M, Kaul P, Hendricks K, Faraone SV: Advances in understanding and treating ADHD. BMC Med 9:72, 2011.

Balakrishnan K, Grieve J, Tordoff J, Norris P, Reith D: Pediatric licensing status and the availability of suitable formulations for new medical entities approved in the United States between 1998 and 2002. J Clin Pharmacol 46:1038-1043, 2006.

Beck MH, Cataldo M, Slifer KJ, Pulbrook V, Guhman JK: Teaching children with attention deficit hyperactivity disorder (ADHD) and autistic disorder (AD) how to swallow pills. Clin Pediatr (Phila) 44:515-526, 2005.

Chavez B, Sopko MA, Jr, Ehret MJ, Paulino RE, Goldberg KR, Angstadt K, Bogart GT: An update on central nervous system stimulant formulations in children and adolescents with attention-deficit/ hyperactivity disorder. Ann Pharmacother 43:1084-1095, 2009.

Childress AC, Kollins SH, Cutler AJ, Marraffino A, Sikes CR: Efficacy, safety, and tolerability of an extended-release orally disintegrating methylphenidate tablet in children 6-12 years of age with attention-deficit/hyperactivity disorder in the laboratory classroom setting. J Child Adolesc Psychopharmacol. 2016 [Epub ahead of print]; DOI:10.1089/cap.2016.0002.

Childress A, Tran C: Current investigational drugs for the treatment of attention-deficit/hyperactivity disorder. Expert Opin Investig Drugs 25:463-474, 2016.

Coghill D, Banaschewski T, Zuddas A, Pelaz A, Gagliano A, Doepfner M: Long-acting methylphenidate formulations in the treatment of attention-deficit/hyperactivity disorder: A systematic review of head-to-head studies. BMC Psychiatry 13:237, 2013.

Concerta 2005 (Full Prescribing Information). Titusville (New Jersey), Janssen Pharmaceuticals, Inc., 2005.
Dowson AJ, Charlesworth BR: Patients with migraine prefer zolmitriptan orally disintegrating tablet to sumatriptan conventional oral tablet. Int J Clin Pract 57:573-576, 2003.

Dowson AJ, MacGregor EA, Purdy RA, Becker WJ, Green J, Levy SL: Zolmitriptan orally disintegrating tablet is effective in the acute treatment of migraine. Cephalalgia 22:101-106, 2002.

Feldman M, Belanger S: Extended-release medications for children and adolescents with attention-deficit hyperactivity disorder. Paediatr Child Health 14:593-602, 2009.

Felt BT, Biermann B, Christner JG, Kochhar P, Harrison RV: Diagnosis and management of ADHD in children. Am Fam Physician 90:456-464, 2014.

Focalin XR 2015 (Full Prescribing Information). East Hanover (New Jersey), Novartis Pharmaceuticals Corporation, 2015.

Heal DJ, Pierce DM: Methylphenidate and its isomers: Their role in the treatment of attention-deficit hyperactivity disorder using a transdermal delivery system. CNS Drugs 20:713-738, 2006.

ICH: ICH Harmonised Tripartite Guideline; guideline for good clinical practice E6. International Conference on Harmonisation, 1996. Available at www.ich.org/fileadmin/Public_Web_Site/ICH Products/Guidelines/Efficacy/E6/E6_R1_Guideline.pdf (Accessed May 20, 2016).

Ivanovska V, Rademaker CM, van Dijk L, Mantel-Teeuwisse AK: Pediatric drug formulations: A review of challenges and progress. Pediatrics 134:361-372, 2014.

Kaufman J, Birmaher B, Brent D, Rao U, Flynn C, Moreci P, Williamson D, Ryan N: Schedule for Affective Disorders and Schizophrenia for School-Age Children-Present and Lifetime Version (K-SADS-PL): Initial reliability and validity data. J Am Acad Child Adolesc Psychiatry 36:980-988, 1997.

Kolar D, Keller A, Golfinopoulos M, Cumyn L, Syer C, Hechtman L: Treatment of adults with attention-deficit/hyperactivity disorder. Neuropsychiatr Dis Treat 4:389-403, 2008.

Marcus SC, Wan GJ, Kemner JE, Olfson M: Continuity of methylphenidate treatment for attention-deficit/hyperactivity disorder. Arch Pediatr Adolesc Med 159:572-578, 2005.

Markowitz JS, Straughn AB, Patrick KS: Advances in the pharmacotherapy of attention-deficit-hyperactivity disorder: focus on methylphenidate formulations. Pharmacotherapy 23:1281-1299, 2003.

Marquis J, Schneider MP, Payot V, Cordonier AC, Bugnon O, Hersberger KE, Arnet I: Swallowing difficulties with oral drugs among polypharmacy patients attending community pharmacies. Int J Clin Pharm 35:1130-1136, 2013.

McCracken JT, Biederman J, Greenhill LL, Swanson JM, McGough JJ, Spencer TJ, Posner K, Wigal S, Pataki C, Zhang Y, Tulloch S: Analog classroom assessment of a once-daily mixed amphetamine formulation, SLI381 (Adderall XR), in children with ADHD. J Am Acad Child Adolesc Psychiatry 42:673-683, 2003.

Metadate CD 2014 (Full Prescribing Information). Smyrna (Georgia), UCB, Inc., 2014.

Orapred 2011 ODT (Full Prescribing Information). Florham Park (New Jersey), Shionogi, Inc., 2011.

Paparella S. Identified safety risks with splitting and crushing oral medications. J Emerg Nurs 36:156-158, 2010.

Pierce D, Katic A, Buckwalter M, Webster K: Single- and multipledose pharmacokinetics of methylphenidate administered as methylphenidate transdermal system or osmotic-release oral system methylphenidate to children and adolescents with attention deficit hyperactivity disorder. J Clin Psychopharmacol 30:554-564, 2010.

Pleak RR: Adverse effects of chewing methylphenidate. Am J Psychiatry 152:811, 1995. 
Polaha J, Dalton WT, 3rd., Lancaster BM: Parental report of medication acceptance among youth: Implications for everyday practice. South Med J 101:1106-1112, 2008.

Posner K, Brent D, Lucas C, Gould M, Stanley B, Brown G, Fisher P, Zelazny J, Burke A, Oquendo M, Mann J. Columbia-Suicide Severity Rating Scale (C-SSRS) Pediatric Baseline Version. New York, NY: The Research Foundation for Mental Hygiene, Inc., 2010.

Ritalin LA ${ }^{\circledR} 2015$ (Full Prescribing Information). East Hanover (New Jersey), Novartis Pharmaceuticals Corporation, 2015.

Saharan VA, Singh A: Fast dissolving/disintegrating dosage forms: Growth from immediate release to sustained release and traditional medicines. Recent Pat Drug Deliv Formul. 9:189-191, 2015.

Swanson JM, Hechtman L: Using long-acting stimulants: Does it change ADHD treatment outcome? Can Child Adolesc Psychiatr Rev 14:2-3, 2005.

Swanson JM, Wigal SB, Wigal T, Sonuga-Barke E, Greenhill LL, Biederman J, Kollins S, Nguyen AS, DeCory HH, Hirshe Dirksen SJ, Hatch SJ, Group CS: A comparison of once-daily extendedrelease methylphenidate formulations in children with attentiondeficit/hyperactivity disorder in the laboratory school (the Comacs Study). Pediatrics 113:e206-e216, 2004.

Thomas R, Sanders S, Doust J, Beller E, Glasziou P: Prevalence of attention-deficit/hyperactivity disorder: A systematic review and meta-analysis. Pediatrics 135:e994-e1001, 2015.

Vyvanse 2015 (Full Prescribing Information). Wayne (Pennysylvania), Shire US, Inc., 2015.
Wigal SB, Childress AC, Belden HW, Berry SA: NWP06, an extended-release oral suspension of methylphenidate, improved attention-deficit/hyperactivity disorder symptoms compared with placebo in a laboratory classroom study. J Child Adolesc Psychopharmacol 23:3-10, 2013.

Wigal SB, Gupta S, Greenhill L, Posner K, Lerner M, Steinhoff K, Wigal T, Kapelinski A, Martinez J, Modi NB, Stehli A, Swanson J: Pharmacokinetics of methylphenidate in preschoolers with attentiondeficit/hyperactivity disorder. J Child Adolesc Psychopharmacol 17:153-164, 2007.

World Medical Association: World Medical Association Declaration of Helsinki: Ethical principles for medical research involving human subjects. JAMA 310:2191-2194, 2013.

Wolraich ML, Doffing MA: Pharmacokinetic considerations in the treatment of attention-deficit hyperactivity disorder with methylphenidate. CNS Drugs 18:243-250, 2004.

Zofran 2000 ODT (Full Prescribing Information). Research Triangle Park (North Carolina), GlaxoSmithKline, 2000.

Address correspondence to:

Carolyn Sikes, PhD

Vice President of Clinical Affairs Neos Therapeutics, Inc. 2940 N. Highway 360

Grand Prairie, TX 75050

E-mail: csikes@neostx.com 